\title{
Implantação de Rede CAD/CAM/DNC em uma Indústria no Rio de Janeiro
}

\author{
Heitor Mansur Caulliraux
}

\section{Almaisa Monteiro Souza}

\section{Miriam Izu}

Grupo de Produção Integrada

\section{COPPE/UFRJ}

Programa de Engenharia de Produção

Cidade Universitária - Ilha do Fundão Cx. Postal 68507

Rio de Janeiro - RJ CEP: 21.945-970

Palavras-chave: tomada de decisão estratégica, automação, CAD, CAM, DNC, ciclo do produto.

Key-words: Strategic decision-making, automation, CAD, CAM, DNC, product cycle.

\section{RESUMO}

O presente trabalho tem por objetivo apresentar o processo decisório realizado em uma empresa industrial do Rio de Janeiro, líder em seu sefor, para implantação de uma rede de engenharia CAD/CAM/DNC. A implantação da rede de engenharia permitirá uma otimização nos processos de criação, modificação e análise de um projeto. Permitirá, também, o uso de computadores para ajudar a planejar, gerenciar e controlar as operaçōes de uma planta de manufatura, através de uma interface de computador direta com os recursos de produção da planta.

\section{ABSTRACT}

This paper discusses the decision process to develop an engineering net, based on CAD/CAMDNC technology, in an industrial firm in Rio de Janeiro. This implementation will allow an improvement of the product development process. It will also allow the planning and controlling of the operations in a manufacturing plant through direct links with production resources. 


\section{Introdução}

Apresentaremos, neste trabalho, os resultados de uma pesquisa relacionada com processos de Tomada de Decisão, realizada em uma empresa industrial do setor metal-mecânico do Rio de Janeiro. Foi dada ênfase ao estudo de um caso recente, a implantação da "Rede de Engenharia CAD/CAM/DNC".

Adotamos, como base para nossos estudos, o modelo proposto por Mintzberg et Alii (1976). Este modelo define umadecisão como um compromisso especifico para ação, (geralmente comprometimento de recursos) e um processo de decisão como um conjunto de ações e fatores dinâmicos que começam com a identificação de um estímulo para ação e termina com o comprometimento para ação. Desestruturado refere-se a processos de tomada de decisão que não tenham sido encontrados da mesma forma, e para os quais não exista um conjunto ordenado de respostas na organização.

Estas descrições sugerem que um processo de decisão estratégico é caracterizado pela novidade, complexidade e por ter um fim em aberto. Além disso, a organização geralmente começa com pouco conhecimento de como construir a solução, com apenas uma vaga idéia de como a solução deveria ser, e como a mesma irá ser avaliada quando for desenvolvida.

A metodologia utilizada nesta pesquisa se baseou em entrevistas não estruturadas, segundo Ander-Egg (1978) com perguntas abertas ou não diretivas, visando levantar os fatos que levaram à implantação da rede. Como esta era recente, os tomadores de decisão tinham em mente todos os passos decorridos durante sua implementação.

\section{Modelo}

O modelo ( figura 2.1) apresenta três fases: identificação, desenvolvimento e diagnóstico.

\section{Fase de Identificação}

Apresenta duas rotinas:reconhecimento e diagnóstico. Na rotina reconhecimento, as oportunidades, os problemas e crises são reconhecidos e evocam uma atividade decisória. No diagnóstico, o tomador de decisão tenta compreender os estímulos e determinar as relações de causa e efeito para a situação de decisão.

\section{Fase de Desenvolvimento}

Apresenta duas rotinas:busca e projeto. Esta é a etapa primordial do processo, onde um conjunto de atividades leva ao desenvolvimento de uma ou mais soluções para o problema. No desenvolvimento consome-se um tempo bastante razoável entre a procura de soluções e o projeto.

A busca é feita para encontrar soluções já prontas (dentro e fora da organização). Esta busca pode ser passiva (espera-se por alternativas), ou pode ser feita a ativação de "geradores de busca" para produzir alternativas. A busca ativa é a procura direta de alternativas, ou explorando uma vasta área, ou então focando estreitamente.

$\mathrm{Na}$ rotina de projeto as decisões caem em dois grupos: as que têm soluções customizadas e as que têm soluções modificadas. Uma hipótese forte de Mintzberg et alli diz que a organização projeta apenas uma solução customizada inteiramente desenvolvida. 


\section{Fase de Seleção}

Compreende três rotinas: screen, avaliacão/escolha e autorização.

Descarta-se soluções para reduzir o grande número de alternativas prontas por algumas que sejam factiveis; a avaliação/escolha é então usada para investigar as alternativas viáveis e selecionar um curso de ação; finalmente, a autorização é usada para ratificar uma decisão em um nivel mais alto da hierarquia organizacional.

A rotina screen é usada quando se espera gerar mais alternativas prontas do que se possa avaliar. Está mais relacionada a eliminar o que não é viável, do que a determinar o que é apropriado.

A rotina de avaliação/escolha é muito menos significante que o diagnóstico e projeto em vários dos processos estudados por Mintzberg et alli. Particularmente nos casos de soluções customizadas, a avaliação/escolha aparece como um tipo de "enfeite" no processo, usada para ratificar a solução que foi determinada, tanto explicitamente durante o projeto, quanto implicitamente durante a rotina diagnóstico. Pode ser tratada de três modos distintos, a saber: por julgamento, negociação e análise. No julgamento, um indivíduo faz escolhas com procedimentos que talvez não possa explicar. Na negociação, a seleção é feita por um grupo de tomadores de decisão com objetivos globais conflitantes entre si. $\mathrm{Na}$ análise, uma avaliação factual é levada a cabo, geralmente por tecnocratas, seguida de escolha gerencial por julgamento ou negociação.

A rotina de autorizacão ocorre quando o tomador de decisão individual não tem autoridade para comprometer a organização para um curso de ação. Tipicamente, a autorização é buscada para uma solução pronta, depois do processo final de avaliação e escolha. Verifica-se, também, que existem instâncias de procura de autorização para proceder ao processo de decisão, ou no começo, ou durante o desenvolvimento.

\section{Implantação da Rede Local de Engenharia (RLE)}

A Rede Local de Engenharia (RLE) $\mathrm{CAD} / \mathrm{CAM} / \mathrm{DNC}$ consiste em um sistema de computadores conectados entre si, compartilhando um mesmo banco de dados referentes ao Módulo de Engenharia de Sistemas Integrados de Manufatura. A estrutura do sistema é composta de uma rede de 15 estações, um servidor e 6 máquinas CNC instaladas no parque fabril ( figura 3.1). Uma diferença notada na RLE consiste em todas as estações de trabalho possuirem os softwares, permitindo a execução dos trabalhos mesmo que a rede caia.

Antes da implantação da RLE, o Setor de Engenharia Industrial estava dividido em dois: projeto do produto e processo (manufatura) trabalhando isolados. Havia responsáveis distintos para projeto, processo e manufatura. $\mathrm{O}$ projeto era desenvolvido em pranchetas pelos projetistas, não contando com recursos informáticos, tais como o CAD (Computer Aided Design). Esta situação tornava o desenvolvimento de projetos um processo longo e trabalhoso, pois quaisquer modificações nestes acarretavam frequentes retrabalhos.

O banco de dados existente não era amigável, dificultando a busca de informações, levando as pessoas a preferirem fazer um novo 
projeto. Os problemas se repetiam na fase de desenvolvimento dos protótipos na manufatura. Frequentes retrabalhos para tornar os projetos viáveis, eram dificultados pelos problemas acima descritos.

Levando em consideração o quadro existente, podemos dizer que foi surgindo nas pessoas que seriam mais tarde responsáveis pela definição da rede, uma vontade crescente de modificar este quadro. Este conjunto de vontades iniciais foi se definindo e delineando com o passar do tempo, partindo das impressões da situação existente e uma vaga idéia da solução.

Foram procuradas soluções existentẹs no mercado. Outras empresas foram visitadas com o objetivo de se conhecer os sistemas que estavam sendo usados por essas. A equipe que desenvolveu a RLE participou de congressos e seminários, na tentativa de encontrar uma solução que satisfizesse as suas necessidades relativas a software, tais como banco de dados gráfico, CAD e rede. Esse banco de dados gráfico facilitaria a pesquisa e modificação de projetos já existentes. Houve também a consulta a determinados livros e artigos que poderiam apontar soluções.

Foram descartadas soluções que apresentavam banco de dados sem interface gráfica e a solução "turn-key". Pensou-se, também, em desenvolver internamente todo o sistema, com a contratação de um programador utilizando-se o Windows como base. Esta solução foi descartada, pois, além de ser muito difícil e trabalhosa, não apresentava garantia de sucesso. Em relação ao hardware, depois de avaliação técnica/financeira de soluções apresentadas por diversos fornecedores, foi finalmente escolhida a proposta que melhor atendia às suas necessidades.
Foram feitas apresentações ao gerente de negócios de produtos industriais, que autorizou a implantação do projeto RLE, com restrições quanto ao custo e solicitação de suporte da área informática, para definição de equipamentos. Após esta definição, a estrutura do sistema seria integrada ao ambiente existente.

Define-se CAD (projeto auxiliado por computador), como o uso de sistemas de computadores para assistir na criação, modificação, análise ou otimização de um projeto. OCAM (manufatura auxiliada por computador) pode ser definido como o uso de sistemas de computadores para planejar, gerenciar e controlar as operações de uma planta de manufatura através de uma interface de computador direta ou indireta, com os recursos de produção da planta.

O ciclo do produto compreende as várias atividades e funções que devem ser feitas no projeto e manufatura de um produto. O ciclo de produto começa com um conceito, uma idéia para o produto. Este conceito é cultivado, refinado, analisado, melhorado e traduzido para um plano através do processo de engenharia de projeto. Este planoé documentado projetando-se um conjunto de esboços de engenharia, mostrando como o produto é feito, e fornecendo um conjunto de especificações indicando como o produto poderia ser executado, O impacto do CAD/CAM se manifesta em todas as diferentes atividades no ciclo do produto. O CAD é utilizado na conceituação, projeto e documentação do produto. Computadores são usados no planejamento e sequenciamento do processo para realizar estas funções mais eficientemente. Computadores são usados na produção para monitorar e controlar as funções de manufatura. O comando numérico controlado por unidade central de computador (DNC) é um 
sistema que consiste em se ter várias máquinas com CNC, ligadas a um computador . A figura 3.2 apresenta uma ilustração do modelo físico da rede local.

O projeto possui uma data início, mas não possui data fim, pois estará em constante evolução, acompanhando a estratégia da empresa.

\section{Especificação Técnica}

\section{Hardware:}

· servidor $48650 \mathrm{MHz}, 1.2 \mathrm{G}$ disco

· interligação com cabos coaxiais $\mathrm{S} 1$

- estações PC 386-DX40, 8MRAM, $120 \mathrm{M}$ harddisk, co-processador matemático $\mathrm{C}$ 80387, memória de vídeo 1M, placa comunicação NE 1000/2000.

\section{- 6 unidades DNC (Direct Numeric} Control)

$\cdot 1$ fax/modem

- impressoras matriciais/Inkjet

plotter de pena nanquim

\section{Software:}

- geração de desenhos 2D

geração de desenhos 2D

gerenciador de arquivos CAD

- gerenciador de banco de dados

planilha eletrônica

· comunicação de usuários

- computer aided manufacturing

comunicação de unidades DNC

rede Novel

- editor matemático
· apresentação

- rotinas customizadas

- anti-vírus

- acelerador gráfico

- editor/emissor/receptor de fax

- ferramentas

\section{Operação do Sistema}

$\mathrm{Na} 1^{\mathrm{a}}$ fase (1993) - estação de traóalho conectada ao servidor - o usuário poderá:

- elaborar desenho 2D/3D

- cadastrar desenho 2D/3D

- pesquisar arquivo de desenho

- pesquisar dados referentes ao desenho

- elaborar processos em máquinas CNC com co-processador de programas na linguagem particular das máquinas

- desenvolver rotinas de otimização do sistema CAD

- desenvolver rotinas com cálculos matemáticos complexos

- utilizar planilhas eletrônicas

- comunicar com outros usuários

$2^{\mathrm{a}}$ fase (1994-1995):

- elaborar módulos de simulação

- cadastrar folha de operação

- cálculo de custo de manufatura

- análise estrutural/mecânica dos fluidos (CAE)

- documentação (arquivo/pesquisa)

- integração com sistema MRP/MAS-E

- comunicação das máquinas CNC

- conexão com programa de fornecedores 


\section{Vantagens da Implementação}

A integração da Rede CAD/CAM/DNC ao Departamento de Eng. Industrial, aumentará a flexibilidade na fabricação de novos produtos, assim como, também, permitirá trabalhar com um maior nível de complexidade qualquer modificação no projeto e/ou produto final na manufatura.

De posse dessas tecnologias aumenta-se, consequentemente, a produtividade da indústria, reduzindo-se o tempo total de fabricação, sem causar prejuizo na qualidade.

O CAD aumenta a produtividade da Eng. de Projeto, levando a um aumento de eficiência, e permitindo um tempo maior para a criatividade dos projetistas. O CAM/DNC possibilita o planejamento e controle das atividades de manufatura, permitindo-se manter um controle mais rigoroso dos recursos de mão-de-obra, das instalações e prioridades de trabalho.

Podemos dizer que a RLE atingiu os objetivos inicialmente propostos pela empresa, podendo vir a atingir um nivel de redução de seu lead-time de projeto e processo, apoiar o sistema de decisão, aumentar sua margem de segurança, obter informações necessárias em tempo real, integrar a Engenharia ao chão-defábrica, assim como também poder expandirse futuramente, de acordo com as necessidades estratégicas da empresa, por possuir uma arquitetura modular.

\section{Conclusão}

O caso da RLE apresenta um processo de decisão inédito para a empresa, pela sua própria definição, onde não havia rotinas pré- estabelecidas para lidar com este caso. Sua novidade e complexidade foram barreiras a serem vencidas para sua implantação, o que $o$ caracteriza como um processo de decisão estratégico. Neste caso se observa, de forma mais clara, os problemas existentes para gerenciar decisões não estruturadas.

Embora a RLE melhore consideravelmente o processo de lançamento de novos produtos, esse projeto, paradoxalmente, não partiu de Marketing. Segundo eles, a visão do Setor Industrial, por estar vivenciando cotidianamente esses problemas, certamente os levou à idéia do projeto. Hoje, tanto em Marketing quanto em outros setores, o projeto é muito bem visto, porque além de reduzir custos, agilizar novos lançamentos, melhorar a qualidade dos produtos, permitirá uma maior competitividade no mercado externo.

Cabe, no entanto, destacar que o referido projeto não surgiu de uma lógica necessidade empresarial, muito menos sabia-se a quem e onde recorrer ao longo do seu desenvolvimento. Isso nos leva a concluir que o processo de decisão estratégico da RLE não foi pensado e tratado com racionalidade lógica a priori, e, tampouco, houve uma formalização ao longo de todo o processo.

\section{Referências Bibliográficas}

Ander-Egg, Ezequiel. Introducción a las técnicas de investigación social; para trabajadores sociales. 7 ed. Buenos Aires, Humanitas, 1978.

Mintzberg, Henry; Raisinghani, Duru, and Théorêt, André. The Structure of "Un-

- structured" Decision Processes. Administrative Science Quarterly, 246-275, June 1976, volume 21 . 


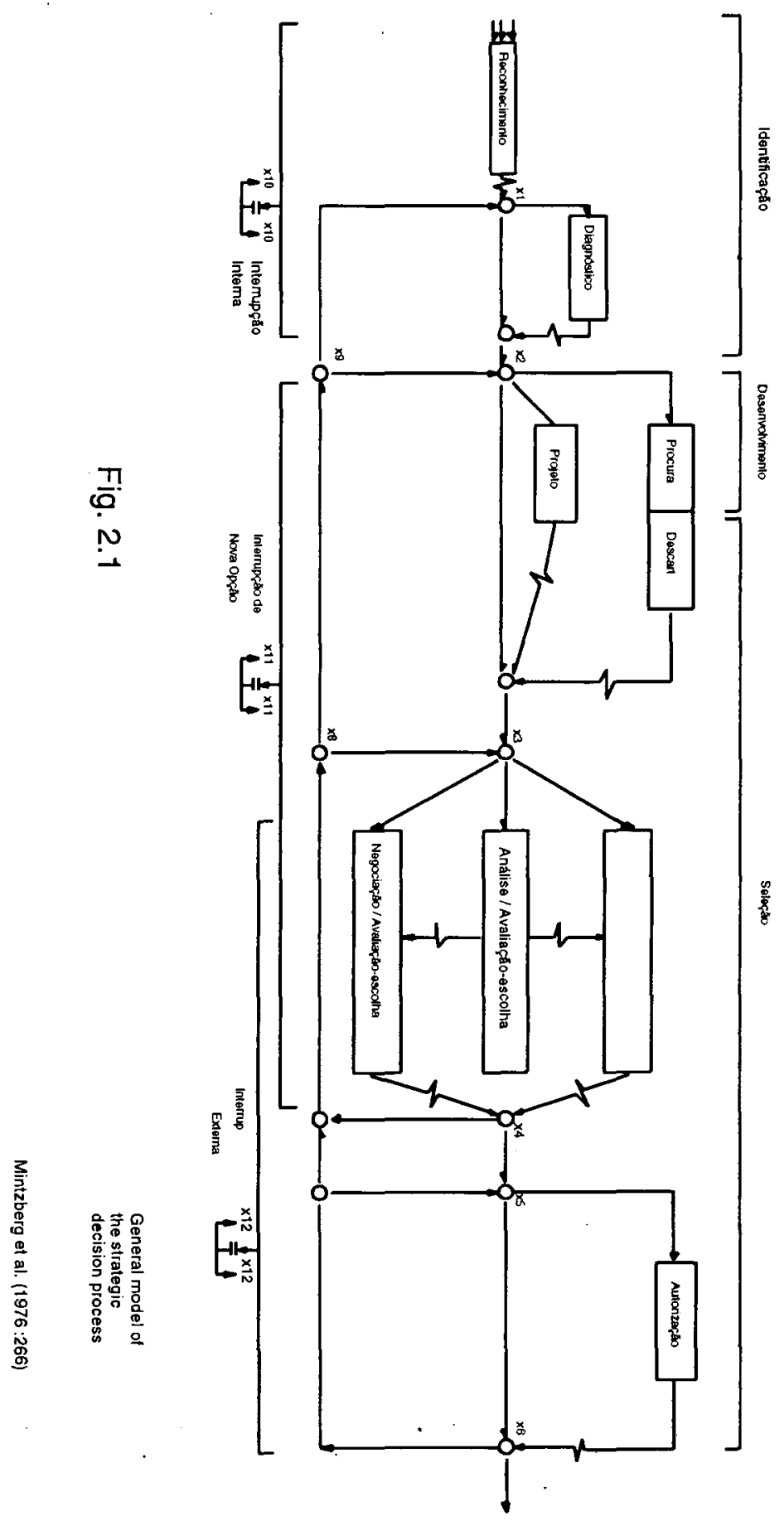




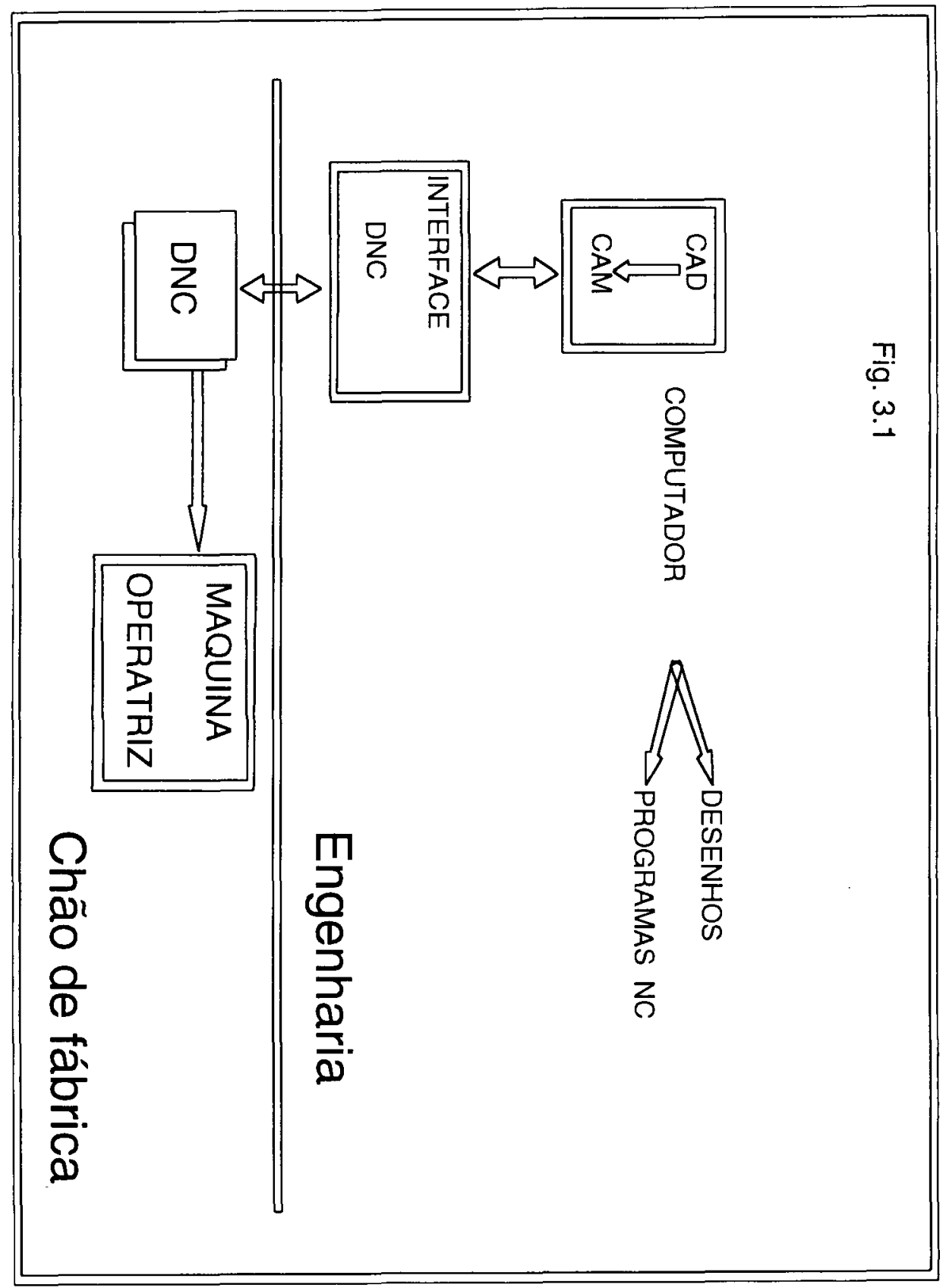




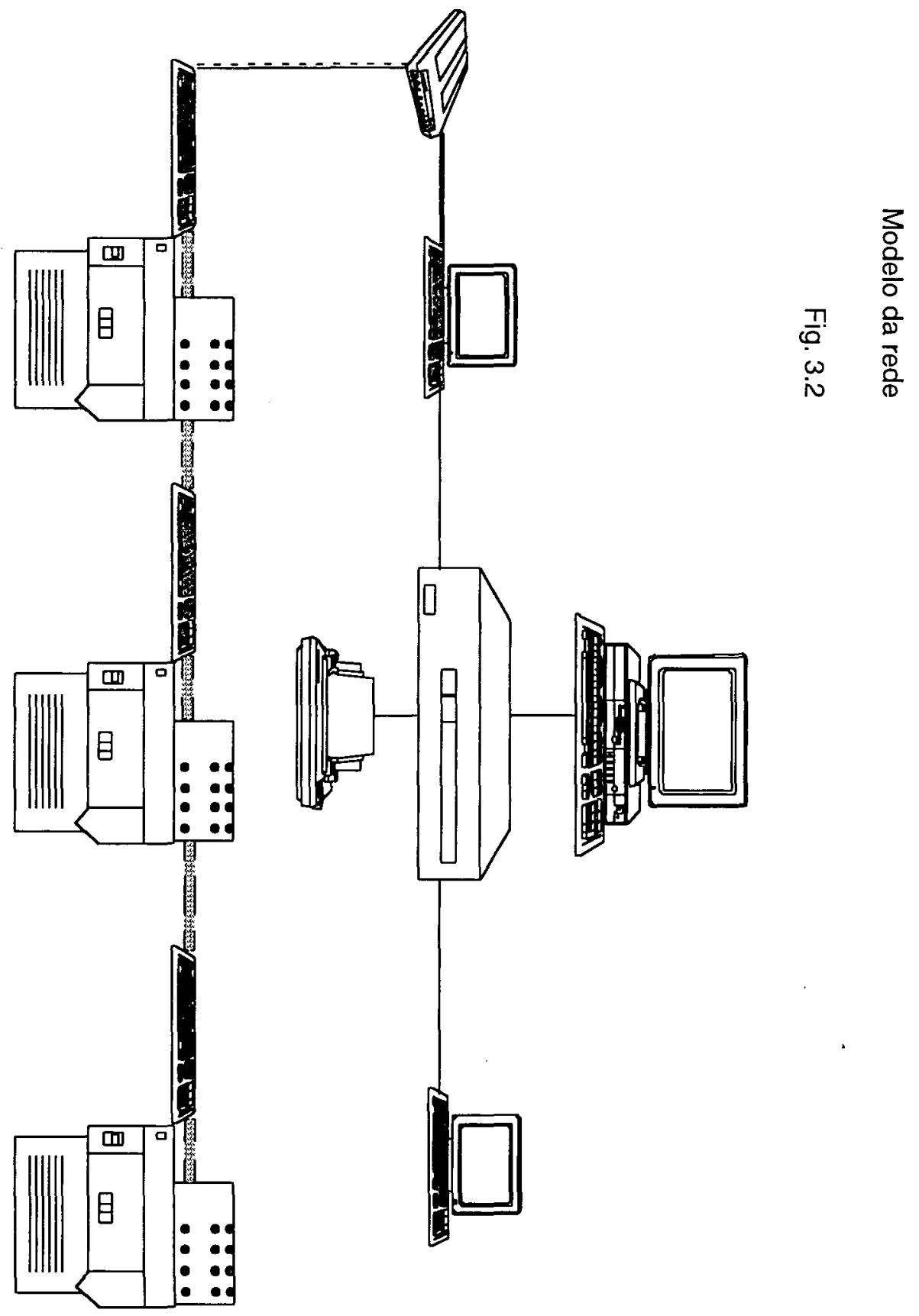

